\title{
CONCEPTUAL FRAMEWORK FOR UNDERSTANDING EMERGING TECHNOLOGIES THAT SHAPE THE ACCOUNTING AND ASSURANCE PROFESSION OF THE FUTURE
}

\author{
Atanasko Atanasovski \\ Faculty of Economics - Skopje, Ss. Cyril and Methodius University \\ atanasko.atanasovski@eccf.ukim.edu.mk \\ Zorica Bozinovska Lazarevska \\ Faculty of Economics - Skopje, Ss. Cyril and Methodius University \\ zorica.bozinovska-lazarevska@eccf.ukim.edu.mk \\ Marina Trpeska \\ Faculty of Economics - Skopje, Ss. Cyril and Methodius University \\ marina.serafimoska@eccf.ukim.edu.mk
}

\begin{abstract}
We are currently on the verge of the fourth industrial revolution (industry 4.0) that will fundamentally change the way in which businesses and individuals operate. It is characterized by the integration of both physical and virtual world with a new pulse for greater automation and autonomy of business processes without or limited need of human intervention. Cloud computing, the internet of things, big data and data analytics, artificial intelligence and machine learning, blockchain, augmented reality are among the most exploited contributing technologies. This paper provides a conceptual framework for emerging technologies with greatest disruptive potential for the accounting and assurance profession. We have surveyed the scarce literature with the aim of investigating the relationship and interplay between most potent emerging technologies and accounting and assurance services. Our findings suggest that cloud accounting, big data, blockchain, artificial intelligence and machine learning will most likely shape the accounting and assurance world for many organisations and future skills set pursued by professionals in order to add value. We conclude that current accounting research efforts are insufficient to understand and grasp the possible future interactions between the vibrant digital economy, its emerging technologies and the accounting profession, including the changing information needs of investors.
\end{abstract}

Keywords: big data, blockchain, accounting, emerging technologies, cloud

JEL classification: $M 15$, M41, O33

\section{INTRODUCTION}

We are witnessing the early days of the fourth industrial revolution commonly referred to industry 4.0 , characterized by the exponential pace of development and fusion of many emerging technologies that fade the borders between physical, digital and bio worlds (Schwab, 2016). Billions of people every day are connected by mobile devices with cost efficient access to increasing computational power, storage capacity and knowledge. Many businesses are looking at substantial increase in efficiency of operations and productivity through combination of advance manufacturing and some of the emerging technologies, such 
as: Internet of Things (IoT), Big Data and data analytics, artificial intelligence and machine learning, robotics, autonomous vehicles, blockchain, cloud computing, augmented reality, nano and biotechnologies, cyber-physical systems, cybersecurity and others. The fast technological breakthroughs will impact many industries such as supply chain and logistics, manufacturing, automotive, information and communication, finance and banking, health. Researchers are arguing that many emerging technologies that are part of industry 4.0 will likely transform the accounting profession, the nature of accounting processes and the future roles and tasks performed by accounting professionals (Bhimani and Willcocks, 2014; Cong et al., 2018; Kokina and Davenport, 2017; Moll and Yigitbasioglu, 2019).

The aim of the paper is to provide a comprehensive conceptual framework for understanding the impact of most disruptive technologies for the accounting profession: cloud computing, Big Data, artificial intelligence and machine learning and the blockchain technology. The framework is built through extensive and combined literature review of research papers, applicative studies and industry articles in order to achieve comprehensive view on the implications of industry 4.0 on accounting processes and professional practice. We explore both strategic and operational aspects of the digital transformation of accounting practice, focusing on the areas of financial accounting and reporting, management accounting and auditing and assurance.

The paper contributes the literature on digitalization in accounting through conceptual and explanatory analysis of:

- main technology developments, proof of concepts and application tools for accounting and assurance activities,

- the nature of technology enabled accounting processes of the future, internal control mechanisms, fraud detection and prevention activities and assurance procedures,

- industry 4.0 implication on workplaces and roles associated with the accounting and assurance profession,

- knowledge and skills gap that accountants need to fulfil in the future.

The rest of the paper proceeds as follows. In section 2 we conduct a literature review on disruptive technologies for accounting. Specifically we explain the advantages and limitations in exploiting cloud computing in accounting, implications of Big Data phenomenon and data analytics for accountants analyzing performance, assessing business risk or perform technology enabled assurance procedures supported by artificial intelligence and machine learning. We conclude section 2 with exploratory study of the blockchain and its potential impact on accounting information and control systems through implementation of public distributed ledger and smart contracts. The next section provides an overview of the future role of accounting professionals and the changing needs for knowledge and skill sets amid young entrants in the profession. Section 4 concludes the paper with a discussion of the limitations and proposals for future research.

\section{TECHNOLOGIES THAT WILL SHAPE THE ACCOUNTING AND ASSURANCE IN THE FUTURE}

The digital transformation of businesses supported by innovative and disruptive technologies of the fourth industrial revolution (industry 4.0) is happening with accelerated pace in many businesses that are part of the global supply chain, advanced manufacturing, logistics, finance and health. Many of these emerging technologies will have profound effect on accounting processes and professional practice, including labour market and job opportunities for accountants. Among the technological innovations that are driving changes in current accounting practices, researchers emphasize the disruptive potential of cloud accounting, big 
data and data analytics, artificial intelligence and machine learning and the blockchain (Kokina and Davenport, 2017; Moll and Yigitbasioglu, 2019).

\subsection{Cloud accounting}

Cloud computing is the provision of computing resources as ready to use services over the internet instead of providing traditional IT infrastructure in terms of selling and installing hardware and software and building capacity within organizations. In general cloud computing services fall into three broad categories (Du and Cong, 2010):

- Data storage as a service of storing and managing large volume of business data remotely on the servers of the cloud service provider,

- Application software as a cloud service where the cloud service provider offers various business software application and tools over the internet for handling business processes such as sales and customer relationship management, purchases or human resources management,

- Infrastructure/platform category where cloud service provider offers computing services of computer hardware and system software, which involves operating systems, security and network systems.

According to Mulholland et al. (2010) there are four possible variants of cloud deployment models, including public cloud, private cloud, community cloud and hybrid cloud. Public clouds are available to the general public, where data is created and stored on third party servers. The service providers offer the server infrastructure and service both free of charge or on pay-per-use basis. Private clouds are internal, usually corporate cloud systems that are no different in architecture compared to public cloud with exception to access rights being limited to company employees. In the community cloud deployment model several organisations with similar backgrounds share the infrastructure and related resources. The hybrid deployment model exists when there is a composition of two or more cloud approaches (private, community or public) which are connected together by standardized or proprietary technology that enables data and application portability.

Most of organizations and individuals are using cloud services provided through the public cloud deployment model, since there are multiple benefits of this model compared to other approaches. It allows companies to pay as they use the service, so they can easily monitor and control usage or predict future expenses as they scale up the use of service (Du and Cong, 2015). The capital investment in IT equipment and its maintenance is responsibility of the cloud service provider, so organizations could allocate more resources and build competence around their core business (Du and Cong, 2015; Mulholland et al., 2010). Another benefit is the cost effectiveness of cloud and additional application services offered simultaneously to a broader range of organisations (Bhimani and Willcocks, 2014; Mulholland et al., 2010).

Nowadays, increasing number of companies of different size rely on a cloud platform software for accounting purposes. Accountants and other employees spend less time in backing up their data with cloud solutions and also could access data and information anytime from anywhere as long there is internet access. Many cloud solutions providers are increasingly offering mobile apps that support monitoring, control and data analytics activities of managers. For multinational companies cloud ERP is more of a prepacked solution and contributes to better integration of the accounting information system on consortia level in comparison to traditional customized ERP solution that may differ significantly across various subsidiaries. For small and medium size accounting practices the cloud accounting software means more flexibility at workplace and vastly improved efficiency in accounting processes since they need to spend less time in communicating 
accounting information with clients who have direct access to real-time information to support their financial decision-making. ERP systems are changing and vendors while keeping their interfaces and basic structures of business processes are transferring their solutions from company-located relational database towards emerging cloud technology. Also, according to Cong et al. (2018) the ERP market is changing with new more mobile and technology savvy market entrants, taking significant market share from larger and less agile firms that dominated the industry traditionally.

The decision to move towards cloud accounting software is not without drawbacks and limitations that must be considered by organisations. Generally, the service reliability of the cloud provider and reliability of the internet are a major concern for user organisations ( $\mathrm{Du}$ and Cong, 2010). In addition data security and confidentiality are relevant concern, since user organizations could always have doubts how their data is being handled or possibly misappropriated. According to a survey conducted by Quinn et al. (2014) the primary reason for not adopting cloud technology for financial accounting processes are concerns about data security and protection. Approximately one third of respondents who decided not to move towards a cloud technology indicated no efficiency gains as a reason. Service performance quality, data ownership and regulatory compliance issues should also be considered by user organisations. Many organisations will decide to maintain full control of the communication and sharing of data and information with regulatory authorities and rather choose to build inhouse capacity than going for cloud solution. Depending on the jurisdiction, authorities could have easy access and directly exchange client data and information with the cloud service provider, which can be often disadvantageous for cloud service users. There is also a going concern risk with the cloud service provider. If the cloud service organization goes out of business or significantly disrupts its operation, it will create significant interruption or even threat business continuity of user organisations. Businesses may also experience situation of being stuck with certain vendor as cloud service provider, unable to change easily the service provider without incurring significant costs or changing complete systems (Quinn et al., 2014).

The cost effectiveness and other benefits make cloud accounting solutions more attractive for small and medium size companies that usually lack resources to invest heavily in IT infrastructure. Internationally, many small businesses are adopting cloud solutions for a single or multiple business processes, including accounting for transactions, preparation of financial information and financial management. According to a survey conducted by national statistical authorities, $26 \%$ of enterprises with more than 10 employees in EU used cloud computing in 2018, mostly for hosting e-mails or storing files in electronic form. Around $10 \%$ of EU companies with more than 10 employees use advanced cloud services relating to financial and accounting software applications (Kaminska and Smihily, 2018). The statistics varied significantly among different EU member states. For example, in countries such as Finland, Sweden, Denmark or Norway roughly a third of surveyed companies where relying on cloud solution for financial and accounting purposes.

\subsection{Big data, data analytics and artificial intelligence}

The advancement of modern digital technologies around the internet and mobile technology has accelerated the trend of data generation and helped the creation of the big data phenomenon. Nowadays, globally produced data doubles every 18 months and organisations collected more data in the past 2 years than in previous 2000 years (Warren et al., 2015). Big data are large datasets with size that goes beyond the capacity of relational database and ability of traditional database software and tools to manage and effectively analyse the data. To fully understand the concept of big data a more holistic view is needed, since the concept 
entails not only the data, data storage and computation power, but the new generation of IT tools and architecture for data analytics, identification of economic, social and technological patterns and provisions of valuable and actionable insights.

Gartner (2016) defines big data as high-volume, high-velocity and/or high-variety information assets that demand for cost effective and innovative forms of information processing that can provide for enhanced insight, decision making and process automation. Volume, velocity and variety are the three Vs that typify big data as vast amount of data created from different sources. Volume relates to the magnitude of the data in terms of huge storage requirements or large number of records. Velocity signifies the increase rate or frequency at which data is being generated and delivered. Variety means great diversity of the type of data being generated, and it might include structured and unstructured data such as e-mail messages, social media postings, phone calls, web traffic, GPS data, pictures and videos. The data derives from different sources such as industrial and individual users' sensors, satellites, social media feeds, photos or data created from various internet sources and physical devices (GPS on cars and phones, phone signals, cameras etc.). Over time additional Vs have been introduced, namely veracity and value (Fosso Wamba et al., 2015; White, 2012). White (2012) highlights the importance of veracity dimension of big data being the quality of the data and the level of trust in various data sources. If big data is insufficient in quality, when integrated with other data and information a false correlation could be made resulting in incorrect business analysis and decision making. The value dimension of big data relates to the economic benefit that is hidden and needs to be identified, transformed and extracted through analysis among larger body of structured and unstructured non-traditional data.

For accountants engaged in financial accounting and preparation of general purpose financial statements, big data may enhance their ability to understand assets, their features and conditions, including market opportunities for assets and related products. This can support the quality of fair value accounting or enable construction of new methods for valuation of intangible assets especially those that are currently not recognized in accordance with accounting standards, such as: customer base, the value of the brand, human resources or commitments (Vasarhelyi et al., 2015; Warren et al., 2015). Data generated from B2B (business-to-business) and B2C (business-to-customer) interactions, including data generated in the internal organization environment from devices with RFID or GPS chips could enrich the available data for accounting valuation and disclosure purposes. Valuation of assets such as inventories and PPE could move from historical cost towards more current estimates of value. FIFO, weighted average cost, measurement of historical cost of PPE and annual accounting estimate of depreciation are largely inaccurate compared to valuation based on information that could be obtained using the modern technology. For example, sensor data on machinery could be used to charge depreciation expense for a period that reflects more accurately the actual utilization of the asset and related benefits.

Furthermore, companies nowadays on average invest more in intangible relative to physical assets, many of which are not measured and shown on the balance sheet. This results in decline in relevance of traditional financial statements being less useful for investors with a growing gap between capital market indicators and reported company earnings (Lev, 2018; Lev and $\mathrm{Gu}, 2016$ ). Big data analysis could help the creation of key value indicators for intangible assets for reliable accounting measurement and recognition in financial statements. Regardless of accounting valuation and recognition, if the indicators are properly disclosed to stakeholders in the notes or the annual report could increase their relevance for business and investment valuation purposes.

The decision making of investors is affected not only by financial statements, but also by exogenous data from sources such as social media, locational data, web path analytics and 
electronic sales data (Cong et al., 2018). Krahel and Titera (2015) argue that business today actively seek to capitalize on the massive volume of available data and metadata, while accounting and auditing standards trail behind with traditional emphasis on presentation, aggregation and sampling rather than the added value of information. Financial reporting standards need to become more dynamic and focused on data, processes that generate them and their analysis, so financial reporting could regain relevance. Accounting processes performed need to be adjusted to incorporate wide-ranging data capturing and analysis activities, resulting in financial reports that contain more unstructured events information related to customers that better reflects on future economic value creation (Bhimani and Willcocks, 2014).Through introduction of Big Data analytics corporate reporting can change its approach and accelerate its move towards real-time reporting with emphasized prospective element of information content (Al-Htaybat and von Alberti-Alhtaybat, 2017; Krahel and Vasarhelyi, 2014).

Certainly there are some practical considerations when integrating big data in accounting analysis, such as the ability of accountants to use tools and technology to analyse data, integrate and correlate big data with traditional financial and non-financial data and the ability to transform accounting processes and measurement practices accordingly.

The management accountant too could utilize the technologies used to extract and analyse textual data from social media in order to evaluate product performance and customer satisfaction instead of using traditional customer satisfaction surveys. Social media (Facebook, Instagram, twitter etc.) is the fastest growing and one of the most important sources of textual data which if analysed appropriately could provide quality information supporting the decision making process. In addition, customer posts on company websites, chat rooms, audio data from phone calls, video reviews posted on the internet by customers and bloggers could add to the analysis.

Management accountants are responsible for creating management control systems that need to gather data and analyse whether the performance and behaviour of employees is aligned with organizational goals. If the organizational management control system is based on the popular balance scorecard framework, the management would like powerful decision-making information that analyses organizational performance in financial, customer, internal business processes and learning and growth perspective. Big Data analysis could expand and improve performance metrics used within the system. Analysis of employees' web and social media use in working hours could provide information relevant for internal business processes and learning and growth perspective. Customer social media posts, review posts on external web pages and vocalic tone of customer services calls could provide valuable information for customer perspective evaluation. According to Warren et al. (2015) Big Data can transform traditional management control systems in comprehensive monitoring and control systems. The use of Big Data analysis could persuade more organizations to move from traditional inward focused budgeting activities towards beyond budgeting practices. New information streams and data outside of the internal ERP system can improve operational planning, performance evaluation, communication of goals and strategy formation.

The Big Data phenomenon has a potential to disrupt and transform the auditing and assurance services industry as well. Today, Big Data analytics is used by increasing number of businesses which chose to rely more on technology when providing goods and services to a large customer base. The auditors need to understand the tools used by these companies in order to complete one of their most important goals during the audit, understanding client's business and environment in order to identify an address risks. If companies increase reporting transparency and more frequently disclose data as a result of advancements in digital technologies and Big Data analytics, the relevance of annual financial reporting could 
diminish further and the case for continuous monitoring and assurance services could get stronger.

Currently, auditing standards keep the stance that testing all transactions can be costly and can make the audit inefficient, therefore the basic concept of sampling is well established in the auditing practice. However, the availability of continuous auditing techniques, progressive digitization of transactional data, availability of Big Data sets and developments in audit data analytics will necessitate changes in the auditing standards in the future (Krahel and Titera, 2015). The risk-based approach of the audit will continue, however the assessment of overall audit risk and its components will change. The move towards complete population could decrease detection risk arriving from extrapolating identified misstatements in sampled transactions. However, the assessment of audit risk need to be amended to incorporate complexity of evaluating the sufficiency, appropriateness and reliability of audit evidence obtained through Big Data analytics (Brown-Liburd and Vasarhelyi, 2015). The increased use of GPS devices, RFID chips and other IoT (internet of things) devices will enable auditors to obtain better audit evidence in respect of existence, completeness and valuation assertions for inventories or items of property, plant and equipment. Instead of traditionally vouching transactions against invoices and receipts, auditors could also use nontraditional and unstructured data and information such as photos, videos, GPS and RFID signaling data.

The audit will be enhanced with process mining techniques that will create numerous audit logs after each transaction path is evaluated, approvals of each transaction automatically checked in terms of segregation of duties and the network of people linked with the transaction appropriately traced and tracked (Jans et al., 2010). Big data analytics can enhance fraud risk analysis systems and improve their ability to identify fraud committed by employees'. Text mining and analysis of e-mail messages of employees could identify disgruntled workers and help more accurately predict organizational fraud risk (Holton, 2009). Other approaches in Big Data analytics that can be used to build financial statements fraud detection models are supervised and unsupervised neural networks, genetic programming, sentiment analysis and natural language processing tools, support vector machines or statistical logistic regression models (Gepp et al., 2018).

The idea of employing artificial intelligence in the accounting and audit field is not new and started in the early $60 \mathrm{~s}$, but recent developments in information and technology related to big data and low cost processing power will drive the future impact of this technology. Artificial intelligence and machine learning have limited use to date, however as the technology advances it will be most likely employed for:

- Coding accounting entries and compliance with accounting rules as they change, with limited or no human intervention when accounting standards are updated,

- Improving fraud detection through sophisticated machine learning models for prediction of fraudulent activities,

- Automated review of contracts and other documents and providing support to professionals for more efficient compliance assessment or predictive analytics.

Auditing is particularly appropriate for application of data analytics and artificial intelligence, since it is becoming more challenging to incorporate vast amount of structured and unstructured data to analyse financial performance and business risks associated with a client. Also many audit tasks are highly repetitive and can be automated (Kokina and Davenport, 2017). AI enabled technology can help auditors to locate and extract relevant information from large volume of documents allowing the professional to focus on applying unstructured analysis and judgement in evaluating trends, patterns and anomalies. Traditionally, accountants and auditors have performed algebraic analysis of numbers, but nowadays are increasingly implementing business intelligence and predictive and visual analytics to analyse 
data and communicate effectively. When these tasks are operationally repetitive they can be supported by AI and machine learning.

Several leading professional accounting firms have started adopting cognitive AI technologies. Deloitte partners with many vendors and tries to develop technology enabled cognitive capabilities for audit specific tasks and technology enhanced solutions for clients' business. In 2014 Deloitte US developed AI-enabled document review platform that has automated the process of extracting relevant information from legal contracts, board meeting minutes, invoices, financial statements etc. According to their claims, the platform helped them reduce the time spent or reviewing documents by up to $50 \%$ or more. KPMG built its own portfolio of AI tools called KPMG Ignite, and applied artificial intelligence in predicting future anomalous business events, document compliance assessment for lease and investment contracts and building a call center analytics engine through the use of natural language processing technology (Faggella, 2020).

As explained above, artificial intelligence and machine learning technologies rather replace specific repetitive tasks performed by accounting professionals and are not likely to result in significant loss of human employment in accounting related positions in the future. However, the technology will be increasingly exploited in the future putting more pressure on accountants to develop skills to work alongside AI and machine learning software to perform more efficient analysis, oversee technology enabled external and internal audit processes and work with technology developers for new AI-enabled tools for business uses.

\subsection{Blockchain technology}

A blockchain is peer-to peer distributed ledger technology designed to record all transactions since its creation, in sequential continued archive. The technology gained world-wide popularity through Nakamoto's (2008) bitcoin proposal for peer-to-peer electronic cash system without the need for intermediaries approved by central authority. As explained by Nakamoto (2008) before transactions are recorded on the blockchain they are initiated and broadcasted to all nodes in the network, where each node collects the transactions into a block. In a costly computational process each node tries to find the hash, a number connected to other information in the block. Once found the new block of transactions can be added to the chain and is connected with previous blocks. This so called proof-of-work process is what preserves hackers to update the blockchain with fraudulent data. The described structure of the bitcoin blockchain has the characteristics of decentralization, strong authentication and tamper resistance (Dai and Vasarhelyi, 2017).

Many researchers see potential for the blockchain technology to transform accounting profession and the design of the accounting information systems, aid prevention of fraud in financial statements, increase efficiency, real-time performance and rise assurance levels in the audit (CPA Canada and AICPA, 2017; Dai and Vasarhelyi, 2017; Kokina et al., 2017). The technology could practically introduce in accounting what has been referred as tripleentry accounting mechanism, where each two-party transaction is verified by intermediary creating additional third verification entry (O'Leary, 2017; Schmitz and Leoni, 2019). The authentication of transactions with the technology is done transparently through the verification mechanism that prevents tampering of entries. Today many companies employ ERP systems for recording and reporting on transactions, with implemented IT controls that make it harder to retroactively change the transaction data and manipulate results of operation. However, more or less businesses are into position to manipulate earnings retroactively in traditional ledger environment through posting additional backdated entries since there is no strict requirement in the architecture to publicly verify the genuine nature of the transaction. 
The blockchain technology if implemented could initiate considerable changes to how assurance procedures are being designed and executed by accounting professionals. One of the key features of the technology is the ability to create immutable records. In an audit of financial statements, this means a complete record list since the first transaction entry in the ledger and a comprehensive audit trail prone from corruptive actions of malicious actors.

Auditors have traditionally relied on sampling while performing audit of financial statements, due to high costs of reviewing all transactions and the need to complete an efficient audit. The use of distributed ledger technology such as blockchain could allow for auditing of complete transactions through review of exception reports. In addition, the traditional timing of the audit near or after financial year end, could be changed towards more continuous or real-time audit throughout the year, as transactions are arranged and recorded (Schmitz and Leoni, 2019; Vaidyanathan, 2017).

Since the appearance of the bitcoin, the blockchain technology went through several evolving phases. The first phase relates to cryptocurrency and potential disruption of international financial and payment systems. The second phase are the smart contracts, small autonomous computer programs on the blockchain that execute automatically when terms defined in a contract are met. Smart contracts reduce costs of contract execution allowing for tamper proof execution, block arbitrary activities and fraud by contract parties (Peters and Panayi, 2016; Schmitz and Leoni, 2019; Yermack, 2017). Smart contracts can be employed on accounting blockchain with incremental benefits for the efficiency and automatization of the accounting process. Compliance with financial reporting requirements can be automated, through encoding of accounting rules derived from accounting standards. When certain criteria are met by the underlining transaction, the accounting rule encoded in a smart contract executes and the transaction is recorded autonomously (Dai and Vasarhelyi, 2017; O'Leary, 2017; Schmitz and Leoni, 2019). Also, internal control procedures could be implemented through smart contracts and corrective actions can be perfectly executed in the organization based on predetermined rules. Smart contracts combined with IoT (internet of things) devices and technologies that capture physical conditions and activities (RFID scanners, GPS devices) can automate additional accounting related processes with limited or no employee intervention. Auditors could also make use of smart contracts, audit analytics and machine learning to automate transaction reconciliation procedures, saving time and reducing human errors in audit engagements (Kokina et al., 2017). Although the blockchain technology could largely make the audit and assurance procedures automated, auditors' professional judgement is still needed to challenge complex accounting estimates and management valuations in preparation of financial statements. Also auditors will need to gather evidence for the existence of transactions recorded on the blockchain and verify the consistency of recorded information with the physical world (Coyne and McMickle, 2017; Schmitz and Leoni, 2019).

Yermack (2017) has expressed more radical views on the potential impact of blockchain technology on accounting profession. The firm's transaction and accounting data could be recorded on a public or permissioned blockchain, allowing all interested parties to aggregate accounting data on income statements and balance sheets at any time without a need to rely on the integrity of the management or auditors' efforts and judgments to add credibility. It is unquestionable that many businesses, governments and regulators recognized the potential of the blockchain technology and there is investment enthusiasm among tech savvy business leaders. However, there are many limitations for wider and accelerated adoption in many businesses and purposes. Among the limitations of the technology its lack of scalability, the need for processing power and large transaction costs, interoperability and confidentiality are usually highlighted (Aranda, 2017; Coyne and McMickle, 2017; Kokina et al., 2017). 


\section{CHANGING ROLE FOR ACCOUNTANTS OF THE FUTURE}

One of the most frequent debates around the future of accounting and assurance profession is concentrated on technological developments and innovations that have the highest potential to affect the accounting practice. Many of current accounting processes such as expense management, invoicing, processing accounts receivable and payable are nowadays completed by machines powered by artificial intelligence. There are common arguments that in the longterm future further elements and segments of the profession will no longer require human labour and will be overtaken by robotics and artificial intelligence. In auditing, basic auditing tasks that are designed for entry level positions and young entrants in the profession, such as vouching for recorded transactions and investigating the audit trail, will probably be completely automated in the next decade or two. This will be the result of further development and adoption by the accounting and assurance profession of technologies such as big data analytics, cloud computing, blockchain and further enlargement of the Internet of Things phenomenon. The future role of accounting professionals will be all about using more sophisticated accounting information systems combined with data analytics and supporting technology such as robotics and artificial intelligence to perform comprehensive analysis and report to relevant parties.

According to Bhimani and Willcocks (2014) new possibilities for digitally enabled businesses create information challenges which are opportunity for accounting and finance professionals to adopt more Big Data analytics and fulfil more strategic role in the future. Given the potential of Internet of Things and Industry 4.0 to transform manufacturing and logistics businesses, companies will need to develop IT infrastructure and processes for continuous monitoring, analysis and interpretation of data captured both internally and generated externally. Management accountants will need to gain data analytics skills to use data generated by Industry 4.0 that will help them design modern tools and indicators for monitoring operations and product quality, discover opportunities to reduce costs and contribute management decision-making.

The auditors of the future will have different role in terms of their approach to data and information analysis. They will need to move from fact checking towards analysis of large and unstructured data sets demonstrating skills for in-depth regression analysis and predictive statistics (Krahel and Titera, 2015).

The progressing digitization of the profession will have profound effect on the skills and knowledge that need to be possessed by young graduates entering the profession. It is important for graduates to gain training in IT skills such as automatic identification systems, analytical programming and data mining (Kruskopf et al., 2019). Through education and internship students should strive to learn how to interact with data analytics software and tools, acquaint with cloud computing solutions, artificial intelligence and robotics. The common accounting curricula at many universities need to be updated to incorporate more technology related instructions. Students should also gain more abstract problem solving skills and develop critical thinking ability. In addition to technical or "hard skill", soft skills will become increasingly important too, especially effective communication, adaptability and innovativeness, customer service orientation, strong ethics and conflict solving skills.

\section{CONCLUSION}

Based on our comprehensive literature review on emerging technologies that are part of the fourth industrial revolution, we conclude that the accounting profession much like the global economy, trade and society will undergo significant changes in the decade or two ahead. The transformation of accounting processes and future role of professional accountants has begun, 
driven and enabled by technologies such as cloud computing, big data and data analytics, robotics, artificial intelligence and machine learning, blockchain.

The blockchain technology can increase credibility of accounting information and financial statements through immutable and tamper proof records of accounting transactions, opportunities for public verification of transactions and comprehensive audit trail (Dai and Vasarhelyi, 2017). Smart contracts combined with IoT devices and artificial intelligence technologies can automate recording of transactions and enable perfect compliance with accounting rules (Kokina and Davenport, 2017; Schmitz and Leoni, 2019). In addition, financial accounting and financial statements could increase their relevance for investors through adoption of big data and data analytics for specific assets valuation and disclosure of non-financial information suitable for business valuation purposes (Krahel and Titera, 2015; Vasarhelyi et al., 2015).

The management accountants in the future will support decision-making through enhanced performance reports containing new generation metrics designed with the help of big data analytics on real-time data from social media, RFID chips and GPS devices, review posts from external web pages etc. (Warren et al., 2015).

Many researchers have conceptualized the transformation trends in audit and assurance through advancements in industry 4.0 technologies. The audit in the future will move towards more continuous and real-time audit that performs tests on complete population of transactions rather than relying on sampling. Such changes will be enabled through blockchain based accounting information systems, increased reliance on audit analytics and implementation of artificial intelligence and machine learning for repetitive audit procedures (Dai and Vasarhelyi, 2017; Kokina et al., 2017; Kokina and Davenport, 2017). The internal and external auditors will be able to better access business and fraud risks, predict and prevent fraudulent behavior by employees and fraudulent financial reporting by the management. Their fraud related activities will be supported by data analytics and artificial intelligence systems such as text mining and analysis, neural networks, sentiment analysis and natural language processing (Gepp et al., 2018). Internal control systems relevant for accounting and financial reporting can be enhanced through blockchain based ERP solutions and the use of smart contracts (Kokina et al., 2017).

Our paper contributes the recent and scarce literature on technology developments in the field of accounting and audit, by providing a conceptual framework that considers most potent industry 4.0 technologies and their implications for the future of the profession. Due to the lack of application data and the emerging and rapidly changing nature of these technologies, the research rather conceptualizes the effects and does not provide evidence on the their actual impact, contributions or challenges in implementation. Further research efforts through surveys, interviews with industry innovators and case studies could investigate many conceptual benefits and advantages of these technologies, including their implications for the role and skill set of future accountants.

\section{REFERENCES}

Al-Htaybat, K., von Alberti-Alhtaybat, L., (2017). "Big Data and corporate reporting: impacts and paradoxes", Accounting, Auditing \& Accountability Journal 30, 850-873.

Aranda, D., (2017), Don't Believe All the Hype 2: The Limitations of the Bitcoin Blockchain. Ripple. URL https://ripple.com/insights/dont-believe-all-the-hype-2-thelimitations-of-the-bitcoin-blockchain/ (accessed 07.04.20).

Bhimani, A., Willcocks, L., (2014), "Digitisation, 'Big Data' and the transformation of accounting information". Accounting and Business Research 44, 469-490. 
Brown-Liburd, H., Vasarhelyi, M.A., (2015), "Big Data and Audit Evidence", Journal of Emerging Technologies in Accounting 12, 1-16.

Cong, Y., Du, H., Vasarhelyi, M.A., (2018), "Technological Disruption in Accounting and Auditing", Journal of Emerging Technologies in Accounting 15, 1-10.

Coyne, J.G., McMickle, P.L., (2017), "Can Blockchains Serve an Accounting Purpose?", Journal of Emerging Technologies in Accounting, 14, 101-111.

CPA Canada, AICPA, (2017). Blockchain Technology and Its Potential Impact on the Audit and Assurance Profession.

Dai, J., Vasarhelyi, M.A., (2017), "Toward Blockchain-Based Accounting and Assurance", Journal of Information Systems, 31, 5-21. https://doi.org/10.2308/isys-51804

Du, H., Cong, Y., (2010), "Cloud Computing, Accounting, Auditing, and Beyond", CPA Journal 80, 66.

Du, H., Cong, Y., (2015), "Going Cloud for Agility: Beyond Financial, System, and Control Motives", Journal of Emerging Technologies in Accounting, 12, 153-167.

Faggella, D., (2020). AI in the Accounting Big Four - Comparing Deloitte, PwC, KPMG, and EY [WWW Document]. Emerj, The AI Research and Advisory Company. URL https://emerj.com/ai-sector-overviews/ai-in-the-accounting-big-four-comparing-deloitte-pwckpmg-and-ey/ (accessed 07.12.20).

Fosso Wamba, S., Akter, S., Edwards, A., Chopin, G., Gnanzou, D., (2015). How 'big data' can make big impact: Findings from a systematic review and a longitudinal case study. International Journal of Production Economics 165, 234-246.

Gartner (2016). IT glossary. Available on-line at: <http://www.gartner.com/it-glossary/bigdata/ (accessed 07.12.20).

Gepp, A., Linnenluecke, M.K., O’Neill, T.J., Smith, T., (2018), "Big data techniques in auditing research and practice: Current trends and future opportunities", Journal of Accounting Literature, 40, 102-115.

Holton, C., (2009), "Identifying disgruntled employee systems fraud risk through text mining: A simple solution for a multi-billion dollar problem", Decision Support Systems, IT Decisions in Organizations 46, 853-864.

Jans, M.J., Alles, M., Vasarhelyi, M.A., (2010), Process Mining of Event Logs in Auditing: Opportunities and Challenges (SSRN Scholarly Paper No. ID 2488737). Social Science Research Network, Rochester, NY.

Kaminska, M., Smihily, M., (2018). Cloud computing - statistics on the use by enterprises Eurostat Statistics Explained. available at: https://ec.europa.eu/eurostat/statisticsexplained/index.php/Cloud_computingstatistics on the use by enterprises, (accessed 10.12 .20

Kokina, J., Davenport, T.H., (2017), “The Emergence of Artificial Intelligence: How Automation is Changing Auditing", Journal of Emerging Technologies in Accounting, 14, $115-122$.

Kokina, J., Mancha, R., Pachamanova, D., (2017), "Blockchain: Emergent Industry Adoption and Implications for Accounting" Journal of Emerging Technologies in Accounting 14, 91100 .

Krahel, J.P., Titera, W.R., (2015), "Consequences of Big Data and Formalization on Accounting and Auditing Standards", Accounting Horizons, 29, 409-422.

Krahel, J.P., Vasarhelyi, M.A., (2014), "AIS as a Facilitator of Accounting Change: Technology, Practice, and Education", Journal of Information Systems, 28, 1-15.

Kruskopf, S., Lobbas, C., Meinander, H., Söderling, K., (2019), "Digital Accounting: Opportunities, Threats And The Human Factor", ACRN Journal of Finance and Risk Perspectives 8, 1-15. 
Lev, B., (2018), "The deteriorating usefulness of financial report information and how to reverse it", Accounting and Business Research, 48, 465-493.

Lev, B., Gu, F., (2016). The End of Accounting and the Path Forward for Investors and Managers, Wiley Finance. Wiley.

Moll, J., Yigitbasioglu, O., (2019). The role of internet-related technologies in shaping the work of accountants: New directions for accounting research. The British Accounting Review, Innovative Governance and Sustainable Pathways in a Disruptive Environment 51, 100833.

Mulholland, A., Pyke, J., Fingar, P., (2010), Enterprise Cloud Computing: A Strategy Guide for Business and Technology Leaders. Meghan-Kiffer Press, USA.

Nakamoto, S., (2008). Bitcoin: A Peer-to-Peer Electronic Cash System. unpublished manuscript.

O'Leary, D.E., (2017), "Configuring blockchain architectures for transaction information in blockchain consortiums: The case of accounting and supply chain systems", Intelligent Systems in Accounting, Finance and Management 24, 138-147.

Peters, G.W., Panayi, E., (2016). Understanding Modern Banking Ledgers Through Blockchain Technologies: Future of Transaction Processing and Smart Contracts on the Internet of Money, in: Tasca, P., Aste, T., Pelizzon, L., Perony, N. (Eds.), Banking Beyond Banks and Money: A Guide to Banking Services in the Twenty-First Century, New Economic Windows. Springer International Publishing, Cham, pp. 239-278.

Quinn, M., Strauss, E., Kristandl, G., (2014), "The effects of cloud technology on management accounting and business decision-making", Financial Management 10, 1-12.

Schmitz, J., Leoni, G., (2019), "Accounting and Auditing at the Time of Blockchain Technology: A Research Agenda", Australian Accounting Review 29, 331-342.

Schwab, K., (2016). The Fourth Industrial Revolution, Currency; Illustrated edition

Vaidyanathan, N., (2017), Divided we fall distributed we stand, The professional accountant's guide to distributed ledgers and blockchain, Association of Chartered Certified Accountants.

Vasarhelyi, M.A., Kogan, A., Tuttle, B.M., (2015), "Big Data in Accounting: An Overview”, Accounting Horizons 29, 381-396.

Warren, J.D., Moffitt, K.C., Byrnes, P., (2015), "How Big Data Will Change Accounting" Accounting Horizons 29, 397-407.

White, M., (2012), Digital workplaces: Vision and reality, Business Information Review.

Yermack, D., 2017, “Corporate Governance and Blockchains”,Rev Financ 21, 7-31. 